\title{
Seasonal relationship between normalized difference vegetation index and abundance of the Pblebotomus kala-azar vector in an endemic focus in Bihar, India
}

\author{
Gouri S. Bhunia ${ }^{1 *}$, Shreekant Kesari ${ }^{1 *}$, Nandini Chatterjee ${ }^{2}$, Rakesh Mandal ${ }^{1}$, Vijay Kumar ${ }^{1}$, \\ Pradeep Das ${ }^{1}$ \\ ${ }^{1}$ Department of Vector Biology and Control, Rajendra Memorial Research Institute of Medical Sciences, \\ Agamkuan, Patna-800007, Bihar, India; ${ }^{2}$ Department of Geography, Presidency University, 86/1College Street, \\ Kolkata-700073, West Bengal, India; "Both the authors have equal contribution
}

\begin{abstract}
Remote sensing was applied for the collection of spatio-temporal data to increase our understanding of the potential distribution of the kala-azar vector Phlebotomus argentipes in endemic areas of the Vaishali district of Bihar, India. We produced monthly distribution maps of the normalized difference vegetation index (NDVI) based on data from the thematic mapper (TM) sensor onboard the Landsat-5 satellite. Minimum, maximum and mean NDVI values were computed for each month and compared with the concurrent incidence of kala-azar and the vector density. Maximum and mean NDVI values $\left(R^{2}=0.55\right.$ and $R^{2}=0.60$, respectively), as well as the season likelihood ratio $\left(X^{2}=17.51 ; \mathrm{P}<0.001\right)$, were found to be strongly associated with kala-azar, while the correlation with between minimum NDVI values and kala-azar was weak $\left(R^{2}=0.25\right)$. Additionally, a strong association was found between the mean and maximum NDVI values with seasonal vector abundance $\left(R^{2}=0.60\right.$ and $R^{2}=0.55$, respectively) but there was only a marginal association between minimum NDVI value and the spatial distribution of kala-azar vis-à-vis $P$. argentipes density.
\end{abstract}

Keywords: remote sensing, Phlebotomus argentipes, normalized difference vegetation index, Kala-azar, India.

\section{Introduction}

Visceral leishmaniasis, or kala-azar, is due to infection by the protozoon parasite Leishmania donovani (Short et al., 1927; Magil, 1995) transmitted through the bites of the female sand fly Phlebotomus argentipes (Swaminath et al., 1942). The poor efficacy of vector control programmes is associated with logistic problems, mainly due to poor understanding of vector ecology. Indeed, knowledge of breeding sites, host preferences and seasonality of $P$. argentipes is crucial when designing effective vector control strategies (Ghosh et al., 1999; Picado et al., 2010). Kala-azar has become particularly common in the north-eastern part of India and is currently considered one of the most severe public health problems of the country (Ashford, 2000; Redhu et al., 2006). The Vaishali district, centrally located in the state of Bihar, is witnessing a situation in which kala-azar is re-emerging with increasing

Corresponding author:

Pradeep Das

Department of Vector Biology and Control

Rajendra Memorial Research Institute of Medical Sciences

Agamkuan, Patna-800007, Bihar, India

Tel. +91 0612263 5570; Fax +910612 2634379

E-mail: dr.pradeep.das@gmail.com impact. An expanding geographical area, generally corresponding to this district, has one of the highest prevalence rates in the nation with approximately $10 \%$ of the population at risk (State Health Society of Bihar, 2007), reflecting a major breakdown of control activities (WHO, 2008).

The combined use of remote sensing and geographical information systems (GIS) facilitates the study of vector-borne, infectious diseases based on the fundamental concepts of landscape epidemiology (Pavlovsky, 1996). Many remotely sensed environmental variables, both abiotic and biotic ones, are relevant for the study of kala-azar transmission as well as for habitat niches of the vector (Nieto et al., 2006; Colacicco-Mayhugh, 2010). For example, vegetation is a risk factor for kala-azar (Dinesh and Dhiman, 1991; Dhiman and Dinesh, 1992), and peridomestic tree plantations constitute a significant risk since they not only provide a dark and humid atmosphere around the houses, but also offer suitable resting sites for the vector. Furthermore, plants rich in fructose attract $P$. argentipes and it is not unusual to see fructose-containing climbing undergrowth supported by bamboo in these surroundings (Dhiman and Dinesh, 1992; Ranjan et al., 2005; Sudhakar et al., 2006). 
The remotely sensed normalized difference vegetation index (NDVI), the most widely used index for vegetation coverage (Tucker, 1979; Myneni, 1995), has broad applications as it fluctuates along with meteorological and environmental variables, which determine biomass and photosynthesis reflecting the distribution of plants and trees. Not only does it allow agricultural managers anticipate variations in productivity and potential harvests (Wall et al., 2008), but it also facilitates the identification of high-risk zones for various vector-borne diseases. The NDVI has been used as indicator for the distribution of the kala-azar sand fly vector leading to rational application of preventive measures (Elnaiem et al., 2003; Gebre-Michael et al., 2004; Bavia et al., 2005; Sudhakar et al., 2006; Bhunia et al., 2010a). Though there are limits to what can be learnt about seasonal kala-azar endemicity from NDVI measurements, the monthly changes of this index can contribute effectively. The objective of the present study was to map and analyse the seasonal kala-azar incidence vis-à-vis preferred $P$. argentipes locations based on geospatial methods and the concept of landscape epidemiology.

\section{Materials and methods}

\section{Study area and cultivation practices}

The Vaishali district of Bihar extends around latitude $25^{\circ} \mathrm{N}$ and longitude $85^{\circ} \mathrm{E}$ (Fig. 1) and includes 1,639 villages (and 170 abandoned ones), which belong to one of the 296 administrative divisions (Panchayats) of the National Foundation of Health of Bihar State (http://mohfw.nic.in/NRHM/DHAP/

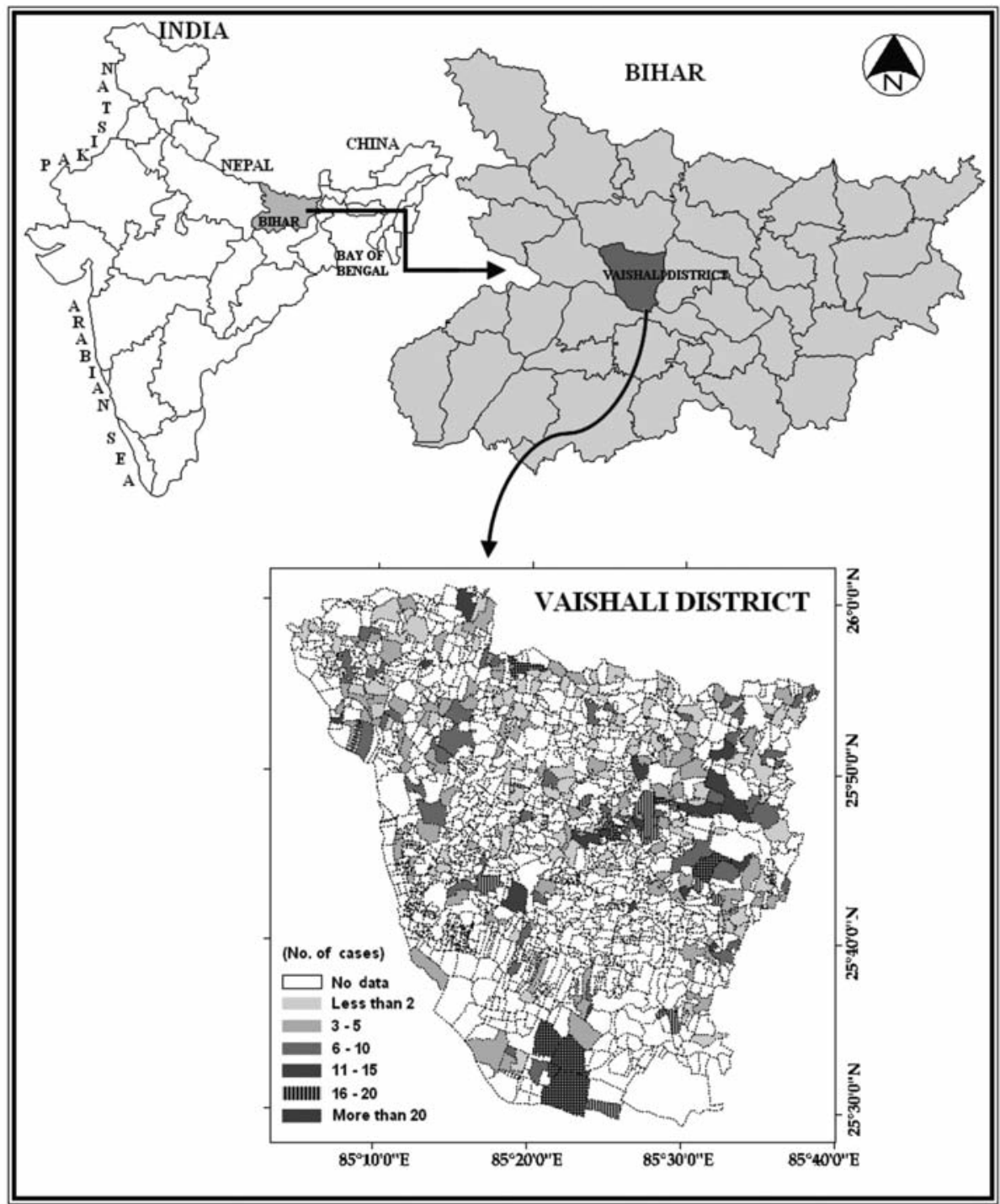

Fig. 1. Map of the study area with indication of its location in India and the state of Bihar. 
DHAP_Bihar/vaishali.pdf). The total population is estimated at 3,495,249 people distributed over 2,036 $\mathrm{km}^{2}$ (http://www.census2011.co.in/district.php). The district is plagued by chronic poverty with around $40 \%$ of the land commonly flooded, whereas $30 \%$ is frequently subjected to drought (http://cgwb.gov.in/ District_Profile/Bihar/Vaishali.pdf). More than 60\% of the population live below the poverty line and the infant mortality rate amounts to 59 per thousand (http://gov.bih.nic.in/Profile/Districts/Vaishali.htm). The climate is tropical and humid with annual average minimum and maximum temperatures of $6{ }^{\circ} \mathrm{C}$ and $44{ }^{\circ} \mathrm{C}$, respectively and rainfall around $1,120 \mathrm{~mm}$ annually (http://vaishali.bih.nic.in/glance.htm). The most common soil type is quaternary alluvium.

Two crops per year are harvested throughout the district, the first cycle starting with the arrival of the monsoon in the latter part of June with planting of rice, maize, sugarcane and arhar (pigeon beans), which are harvested in the post-monsoon season (OctoberNovember). The second crop consists of wheat, tobacco and potato planted during the winter months and harvested by the end of February. Banana and sugarcane constitute the two main crops.

\section{Satellite-based data and NDVI computation}

The remotely sensed data used came from the nearpolar, sun-synchronous Landsat-5 satellite (http://landsat.gsfc.nasa.gov/about/landsat5.html) orbiting the Earth at an average altitude of $705 \mathrm{~km}$ and maintaining a 16-day, 233-orbit cycle. The swath width is $185 \mathrm{~km}$ and the image size $185 \mathrm{x} 170 \mathrm{~km}$. Landsat-5 carries the Thematic Mapper (TM) sensor that provides $30 \mathrm{~m}$ spatial resolution in six spectral bands ranging from blue to the middle infrared, plus a $120 \mathrm{~m}$ resolution thermal/infrared band (Markham et al., 2004). Since the imagery for July and August was unavailable due to high cloud cover, only 10 monthly scenes from the May 2009 to April 2010 period were selected for the time series analysis (Table 1). All data were geometrically corrected to the Universal Transverse Mercator (UTM) projection, zone 45 and the World Geodetic Survey (WGS) 84 datum. This was done using both digitised topographic maps and ground control point (GCP) registration of all scenes. The root mean-square error (RMSE) was around 0.3 pixels which is acceptable according to Lunetta and Elvidge (1998). All images were subsets and masked to show the Vaishali district only. The image processing was completed using ERDAS IMAGINE 9.2 (Leica Geosystems, 2008) software.

The NDVI is defined as the near-infrared band minus the red band (NIR - R) divided by the addition of these values (NIR $+\mathrm{R}$ ) as described by Rouse et al. (1974). The NDVI values range from -1 to +1 with values $\leq 0$ representing water and empty land, while values $\geq 0$ signifies vegetation ranging from sparse to covering (Krishnaswamy et al., 2009). For each monthly image, the NDVI was calculated using the red band (no. 3) and the near-infrared band (no. 4). Ten NDVI continuous images for all dates were selected producing float-data (continuous real numbers). Each image was re-coded as either 0 (water surface or empty land) or 1 (land with vegetation) depending which value was the closest. To validate the way in which land use was indicated, we examined three random points in agricultural areas and three in tree plantations calculating the average NDVI values for the different months. To determine the association between NDVI values of the seasons and the spatial distribution of kala-azar vis-à-vis vector density, a $500 \mathrm{~m}$ diameter buffer zone was used for each survey point.

Table 1. Landsat-5 TM image information for data acquisitions corresponding to path 141/row 42.

\begin{tabular}{|c|c|c|c|}
\hline Acquisition date & Scene identifier & Sun elevation & Sun azimuth \\
\hline May 15, 2009 & LT51410422009135KHC00 & 65.84 & 101.93 \\
\hline June 16, 2009 & LT51410422009167KHC00 & 66.28 & 90.77 \\
\hline September 12, 2009 & LT51410422009199КНС00 & 64.57 & 95.56 \\
\hline October 12, 2009 & LT51410422009295KНC00 & 47.42 & 147.88 \\
\hline November 23, 2009 & LT51410422009327KHC00 & 39.00 & 153.26 \\
\hline December 9, 2009 & LT51410422009343KHC01 & 36.19 & 153.09 \\
\hline January 16, 2010 & LT51410422010042KHC00 & 41.14 & 141.72 \\
\hline February 27, 2010 & LT51410422010058KHC00 & 45.92 & 137.47 \\
\hline March 31, 2010 & LT51410422010090KНC00 & 56.65 & 126.59 \\
\hline April 16, 2010 & LT51410422010106КНC00 & 61.35 & 119.12 \\
\hline
\end{tabular}




\section{Epidemiological data}

The incidence of kala-azar between 2005 and 2010 was obtained from the Bihar State Health Society in Patna and the Malaria Office in Hajipur, both district headquarters for Vaishali. The patients had been diagnosed in the local hospital (Sadar) or in primary health centres on the basis of clinical symptoms and parasite presence in spleen/bone marrow aspirations, identified by the rk39 kit (Srivastava et al., 2011) provided by the national vector borne disease control programme. To identify the spatial kala-azar distribution, a village-level, digital database was generated based on the historical record of the cases reported.

\section{Entomological data}

Sand flies were collected outdoors (cattle sheds) as well as indoors (living rooms) from January 2009 to March 2010 in 50 randomly selected villages using light traps developed at the Center for Disease Control and Prevention (CDC), Atlanta, USA. These traps were installed after sunset (at 6 PM) and collected before sunrise (at 6 AM). For each participating village, 10 traps were placed at randomly chosen locations and the sand fly abundance calculated per trap per night for each village. In the daytime, the traps were stored in a confined place and then reused.

\section{Statistical analysis}

Stata, version 10.0 was employed for statistics as devised by Hamilton (2009). A Pearson's univariate correlation analysis was initially undertaken to establish the relationship between the NDVI, $P$. argentipes abundance and the spatial distribution of kala-azar. We recognised the preliminary association through scatter plots between the dependent variable and the selected independent variables according to the procedure outlined in 'initial identification of relationships'. A preliminary control of the data revealed that it would be more appropriate to estimate the relationship between these three parameters after adjusting for season and auto-correlation based on a polynomial regression model $\left(R^{2}\right)$ investigating up to the third-order rather than simply assuming a linear association. The reason for choosing this model was that it increases the precision of the estimates, since vegetation vigour not only affects disease occurrence and vector abundance in the same month but also in several of the subsequent months. Although regression models based on Poisson distributions are standard for count data (e.g. for the estimation of infectious disease surveillance data), their assumptions are not applicable if the data are overdispersed (Hilbe, 2011). If, for example, the incidence of zero counts is greater than expected, models based on negative binomial distributions produce a slightly better fit (Ridout et al., 1998). Taking vector density into account, negative binomial regression (likelihood ratio, $X^{2}$ ) analysis, as used by Ramaswamy et al. (1994) to allow model-dependent variables describing the data, was applied to predict the seasonal distribution of kala-azar by considering maximum, minimum and mean NDVI values. The statistical significance was defined at the level of $\mathrm{P}<0.05$.

\section{Results}

\section{Disease distribution}

The seasonal distribution of kala-azar in Vaishali is presented in Table 2. The maximum number of new cases $(11.5 \%)$ was seen in April, whereas the minimum number $(5.3 \%)$ was documented for July. The monthly distribution of cases by age for the period 2005-2010 showed that young people were more often infected then adults, in particular children younger than 10 years, who comprised $34.9 \%$ of all cases (Fig. 2). The male-female ratio was 1:1.3.

\section{Vector density}

Three sand fly species were collected at the study site: $64.5 \% \quad P$. argentipes specimens (male/female ratio $1: 0.85), 34.3 \%$ Sergentomiya specimens (male/female ratio $1: 2.51$ ) and $1.2 \%$ P. papatasi specimens (male/female ratio 1:0.55). Table 2 shows the sand fly density (per trap/per night) calculated for each month. The highest densities were found in September (10.09) and October (11.14), and the lowest in January (0.37) and February (0.28). Only the proven vector of Indian kala-azar, $P$. argentipes, was considered in the analysis. The negative binomial regression analysis showed no significant correlation between vector density and monthly kala-azar prevalence $(P=0.745)$. However, when a multivariate regression analysis of sand fly density and NDVI values in different seasons was performed, a significant correlation between season and sand fly density appeared $\left(\mathrm{R}^{2}=0.38 ; \mathrm{P}<0.03\right)$. 
Table 2. The monthly distribution of kala-azar incidence and sand fly density.

\begin{tabular}{lcccc}
\hline \multirow{2}{*}{ Month } & Incidence $(\%)$ & \multicolumn{3}{c}{ Vector density (per trap/per night) } \\
\cline { 3 - 5 } January & 7.3 & P. argentipes & P. papatasi & Sergentomiya \\
February & 10.0 & 0.37 & 0 & 0.19 \\
March & 9.7 & 0.28 & 0 & 2.40 \\
April & 11.5 & 5.12 & 0.29 & 2.98 \\
May & 11.0 & 6.30 & 0.75 & 4.31 \\
June & 9.1 & 5.75 & 0.87 & 3.90 \\
July & 5.3 & 8.26 & 0 & 5.65 \\
August & 8.2 & 4.75 & 0.25 & 5.21 \\
September & 7.3 & 5.95 & 1.25 & 4.59 \\
October & 7.1 & 10.09 & 0.17 & 5.76 \\
November & 7.1 & 11.14 & 0.50 & 4.78 \\
December & 6.4 & 4.59 & 0.17 & 2.59
\end{tabular}

\section{NDVI measurements}

The Landsat-TM satellite images, taken from May 2009 to April 2010, showed the monthly NDVI changes (Fig. 3). They reflect the impact of the monsoon, which normally arrives in June and ends in September and thus produce lower values during the pre-monsoon period, i.e. the summer months of March to May (maximum 0.43) and higher values from June to February during the monsoon and the post-monsoon period (October and November) (Table 3). The NDVI readings are often high in January and February due to the winter rabi crops, but they are low in the paddy fields during planting. The values rise as the rice plants grow and drop when they are cut down only to rise again during harvest. The NDVI measurements can also be used to estimate the predominant types of vegetation since the presence of tree plantations (e.g banana, mango and litchi) generally produce higher NDVI values than agricultural land (Fig. 3).

As seen in Fig. 4, agricultural land produced relatively low NDVI values (0.10-0.20) from May to December and relatively high ones (generally 0.25 to 0.35 but also higher) in January and February. In the pre-monsoon months (March to May), the index varied between 0.01 and 0.15 in more than half of the entire study area $(62.8 \%)$ without any evident, regional differences. NDVI values of $\geq 0.25$ were only seen in $2.2 \%$ of the area. In the post-monsoon months (October and November), low values (0.01-0.15) cov-

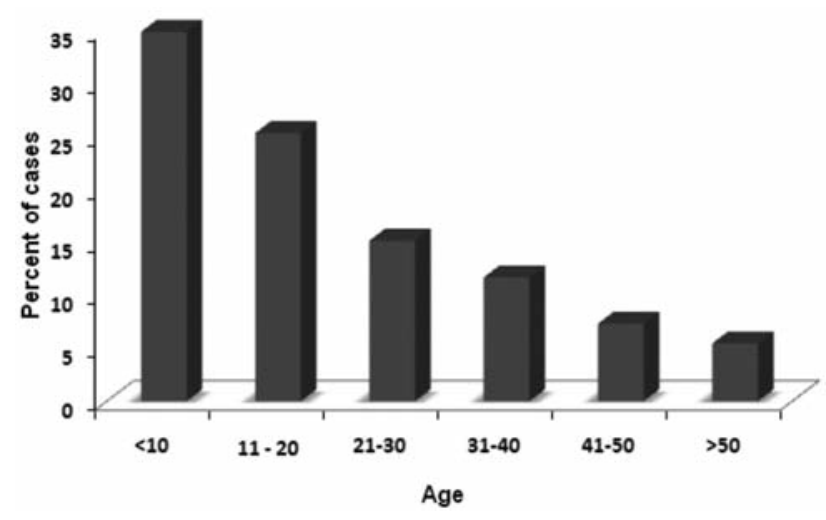

Fig. 2. The distribution of kala-azar by age in the Vaishali district.

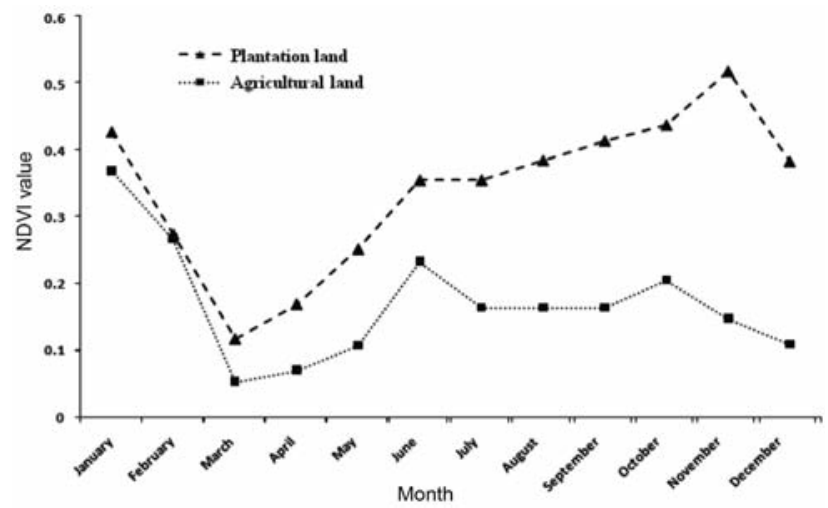

Fig. 3. Monthly changes of NDVI values in agricultural areas and in tree plantions (data from May, 2009 through April, 2010)*.

* Estimates based on the average values for the closest months were used in place of unavailable data for July-August. 


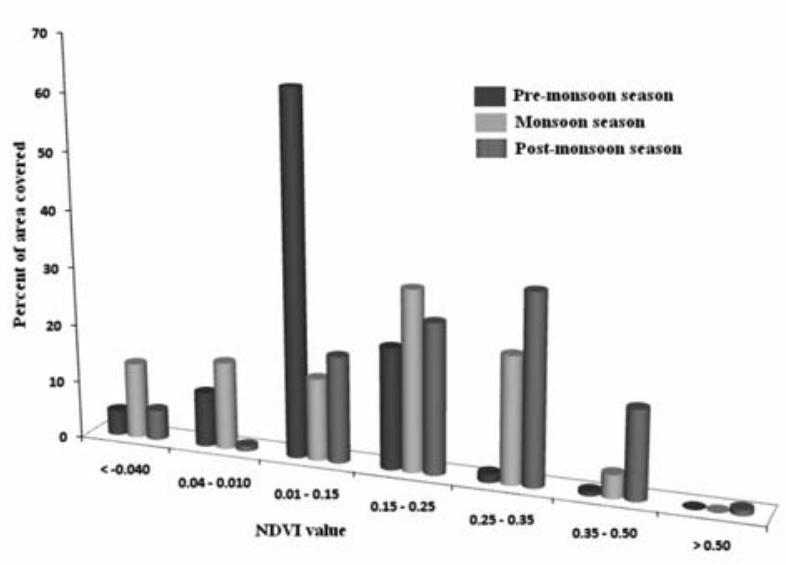

Fig. 4. NDVI values and areas obtained in the Vaishali district in the pre-monsoon (March-May), monsoon (June-August)* and the post-monsoon (October-November) seasons.

* only the value of June is considered here due to unavailability of satellite imagery for July-August.

ered only $18.5 \%$ of the land, whereas the largest part $(32.8 \%)$ showed values of $0.25-0.35$. In the monsoon months (using the figure for June and an estimate based on the closest months due to the lack of JulyAugust satellite imagery), low values of NDVI (0.010.15 ) covered $14.3 \%$ of the total land, whereas the largest part $(31.2 \%)$ had values of $0.15-0.25$ with no area exceeding 0.50 .

\section{NDVI and kala-azar incidence}

The minimum, maximum and mean NDVI values (and standard deviation) were computed on a monthly basis (Table 3 ) and compared to the monthly numbers of kala-azar (old and new cases) between 2005 and 2010 (Fig. 5). The third-order polynomial regression model illustrates the strengths of these relationships, showing a strong correlation between the minimum NDVI and disease incidence $\left(R^{2}=0.77\right)$ as well as a significant association between maximum values and kala-azar $\left(R^{2}=0.55\right)$. However, a weak correlation was found between the mean NDVI values and the disease $\left(R^{2}=0.22\right)$. On the other hand, as seen in
Table 4, the overall analysis of NDVI values and kalaazar (old and new cases), by negative binomial regression analysis, showed a significant correlation both for the maximum and the mean NDVI values and reported kala-azar occurrence (likelihood ratio $\left(X^{2}\right)=17.51$; $\mathrm{P}<0.001)$. However, we found no significant interaction between the minimum NDVI values and the number of cases of the disease.

Overlaying the NDVI map onto that depicting the spatial distribution of kala-azar incidence demonstrated that areas with NDVI values of 0.20 and above generally coincided with areas with high numbers of new cases (Fig. 6). Pre-monsoon, maximum NDVI values were found to have significant negative associations with the spatial distribution of reported cases $(r=-0.65 ; \mathrm{P}<0.001)$, while the mean NDVI values were positively associated with the presence of kalaazar $(r=0.37$; $\mathrm{P}<0.001)$ and minimum NDVI values correlated with kala-azar only weakly $(r=0.10)$. This suggests that the disease has a preference for relatively wet and cool areas.

The maximum NDVI values of the post-monsoon season had significant negative associations with the spatial distribution of kala-azar $(r=-0.58 ; \mathrm{P}<0.001)$, as did the mean NDVI values $(r=-0.53 ; \mathrm{P}<0.001)$. A marginal association was found between the postmonsoon, minimum NDVI values and the spatial distribution of the disease $(r=0.17 ; \mathrm{P}=0.003)$. The areas harbouring most of the cases were found to be situated within zones with scarce vegetation (NDVI values $<0.40$ ). However, in the following few months, the NDVI values were higher, which might have been due to the stage of agricultural production (e.g. rabi crops) and/or plantation of cash crops.

\section{NDVI and vector density}

The analysis of maximum, minimum and mean NDVI values and $P$. argentipes densities, based on the polynomial regression model (Fig. 7), shows that the mean and maximum NDVI values were strongly correlated with the seasonal abundance of $P$. argentipes

Table 3. Descriptive statistics of the monthly distribution of NDVI derived from the Landsat-5 TM data.

\begin{tabular}{|c|c|c|c|c|c|c|c|c|c|c|}
\hline \multirow[b]{2}{*}{ Variable } & \multicolumn{10}{|c|}{ Acquisition date } \\
\hline & $\begin{array}{c}16 \\
\text { January } \\
2010\end{array}$ & $\begin{array}{c}27 \\
\text { February } \\
2010\end{array}$ & $\begin{array}{c}31 \\
\text { March } \\
2010\end{array}$ & $\begin{array}{c}16 \\
\text { April } \\
2010\end{array}$ & $\begin{array}{c}15 \\
\text { May } \\
2009\end{array}$ & $\begin{array}{c}16 \\
\text { June } \\
2009\end{array}$ & $\begin{array}{c}12 \\
\text { September } \\
2009\end{array}$ & $\begin{array}{c}12 \\
\text { October } \\
2009\end{array}$ & $\begin{array}{c}23 \\
\text { November } \\
2009\end{array}$ & $\begin{array}{c}9 \\
\text { December } \\
2009\end{array}$ \\
\hline Minimum NDVI & -0.30 & -0.26 & -0.21 & -0.27 & -0.21 & -0.23 & -0.32 & -0.32 & -0.38 & -0.36 \\
\hline Maximum NDVI & 0.68 & 0.57 & 0.34 & 0.43 & 0.38 & 0.54 & 0.50 & 0.50 & 0.62 & 0.62 \\
\hline Mean NDVI & 0.17 & 0.15 & 0.06 & 0.08 & 0.08 & 0.15 & 0.09 & 0.09 & 0.12 & 0.13 \\
\hline Standard deviation & 0.29 & 0.24 & 0.16 & 0.20 & 0.17 & 0.22 & 0.24 & 0.24 & 0.29 & 0.29 \\
\hline
\end{tabular}


Table 4. Negative binomial regression analysis for predicting kala-azar cases with regard to NDVI values.

\begin{tabular}{|c|c|c|c|c|}
\hline Variable & Coefficient & Standard error & z-value* & P-value \\
\hline Constant & 6.75 & 0.25 & 26.94 & 0.001 \\
\hline Maximum NDVI & -3.10 & 0.71 & -4.37 & 0.001 \\
\hline Mean NDVI & 4.49 & 2.19 & 2.05 & 0.040 \\
\hline Season & -0.12 & 0.05 & -2.35 & 0.019 \\
\hline
\end{tabular}

*The ratio of the coefficient and the standard error. The value follows a standard normal distribution which is used to test against the two-sided alternative hypothesis that the coefficient is not equal to zero.

$\left(R^{2}=0.60\right.$ and $R^{2}=0.55$, respectively), while the minimum NDVI values did not significantly correlate with $P$. argentipes density $\left(R^{2}=0.25\right)$ at the $95 \%$ confidence level. As shown in Fig. 8, the Pearson correlation analysis between the spatial distribution of $P$. argentipes density and NDVI composites values in the pre-monsoon season had a significant negative association with the variables related to maximum $(r=-0.59 ; \mathrm{P}<0.002)$ and mean NDVI values $(r=-0.56$; $\mathrm{P}<0.007)$. A low degree of association was observed between the minimum NDVI values and the spatial abundance of $P$. argentipes during the pre-monsoon season $(r=-0.26$; $\mathrm{P}<0.05)$. In contrast, NDVI composites of the postmonsoon season had a strong negative correlation with the mean NDVI values and the spatial abundance of $P$. argentipes $(r=-0.59 ; \mathrm{P}<0.05)$. Similarly, in the post-monsoon season, the maximum NDVI values were negatively associated with $P$. argentipes abundance $(r=-0.53 ; \mathrm{P}<0.004)$.

The minimum NDVI of the post-monsoon season, on the other hand, had a negative correlation with the spatial distribution of $P$. argentipes density $(r=-0.41$; $\mathrm{P}<0.001)$. In this study, mean NDVI values of $<0.10$ indicated a strong relationship with $P$. argentipes den- sity. When the vector densities were high, the maximum values of NDVI were $\leq 0.35$. In addition, low vector density was also recorded in areas where the NDVI values were $>0.5$. As a result of cross-tabulation based on distribution maps of the monthly count with mean NDVI values <0.03, these areas do account for low $P$. argentipes density.

The analysis on the seasonal prevalence of proven cases (estimate based on new and old cases together) results in a bell-shaped curve, which is in consonance with the seasonal distribution of kala-azar cases as reported by Sanyal et al. (1979). However, no significant correlation was established between sand fly density and kala-azar prevalence. This may be due to the incubation period, which can be highly variable; reportedly ranging from 10 days to $>2$ years (Rees and Kages, 1987; Pearson et al., 1999), which makes a strict seasonal correlation difficult (Jopling, 1955).

\section{Discussion}

It is expected that kala-azar risk areas will expand along with future climate changes, as well as with alterations in the prevailing ecosystem. The relation-

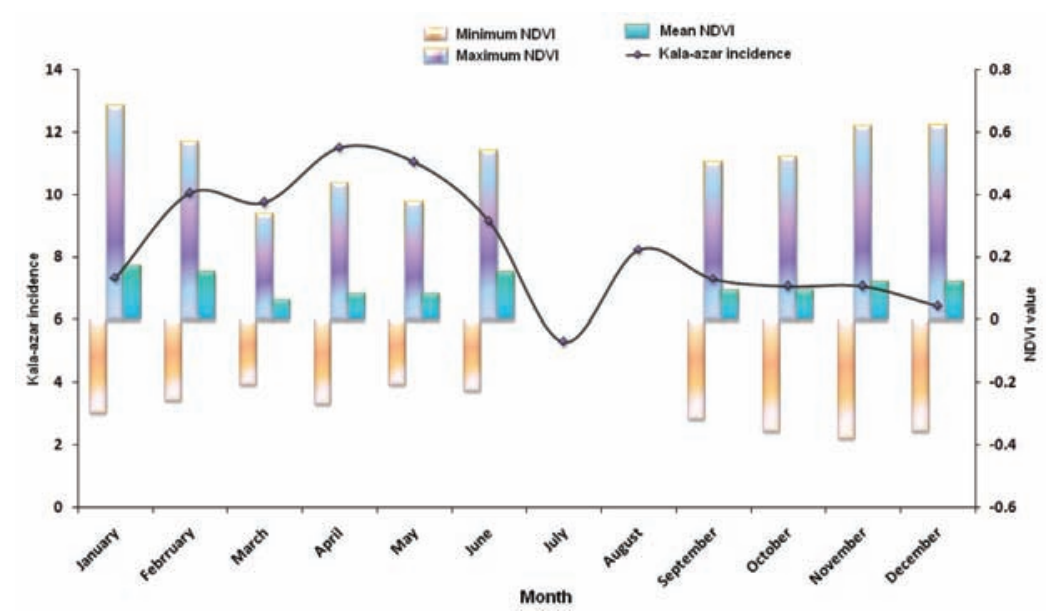

Fig. 5. Relation between the percentage distribution of the monthly kala-azar incidence and the corresponding NDVI values* showing the relation between minimum NDVI and kala-azar; the maximum NDVI and kala-azar; and the mean NDVI and kala-azar.

* Missing NDVI measurements for July-August. 

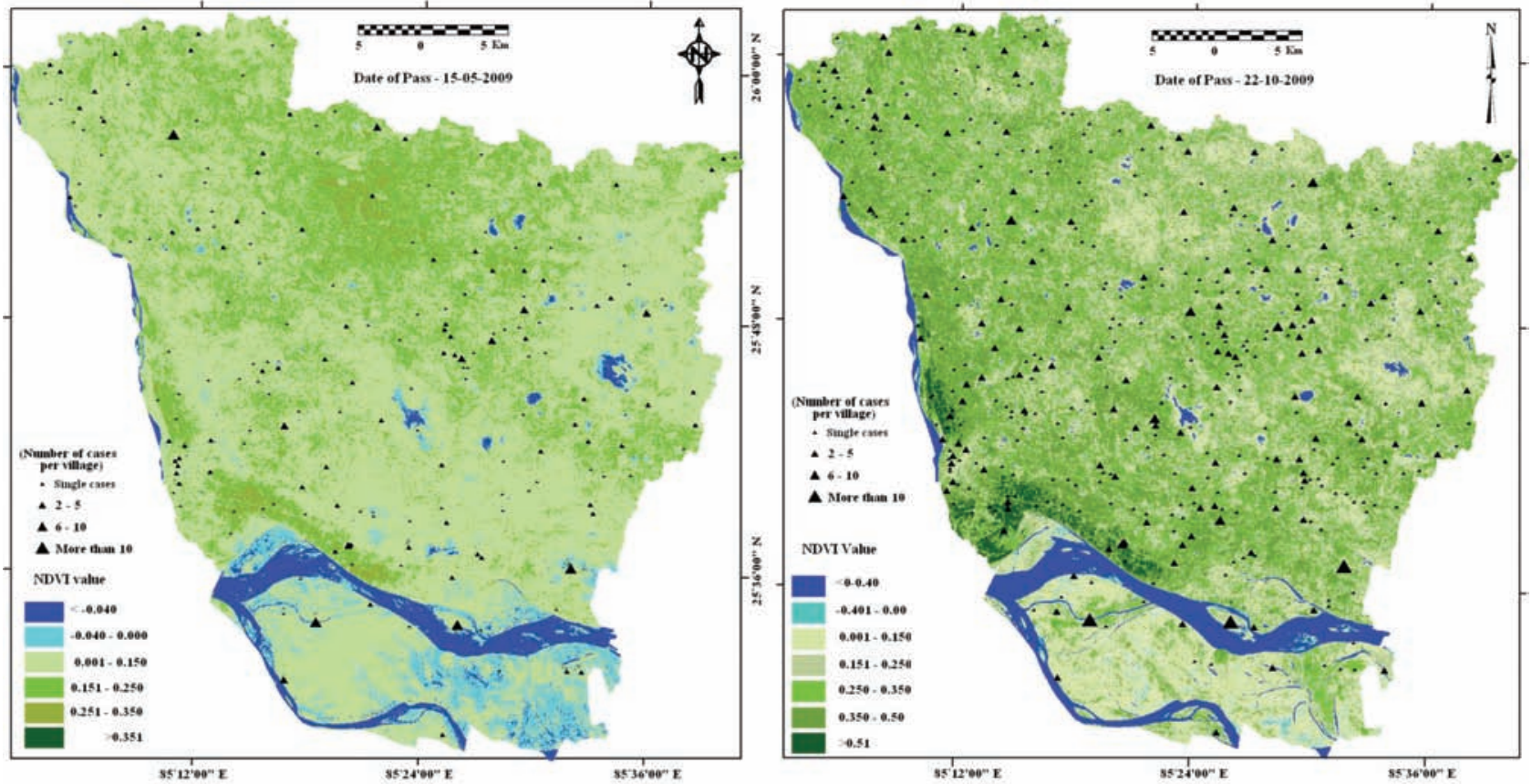

Fig. 6. Distribution of the pre-monsoon NDVI and the kala-azar incidence during summer (A) and the post-monsoon NDVI and the kala-azar incidence during the rainy season (B).

ship between prevalence and NDVI values, including the seasonal patterns, was addressed to draw attention to the need for early warning systems (EWS). Although various parameters can be useful when studying the variation of kala-azar endemicity with respect to dry and wet seasons, observation of the NDVI is a valuable and effective approach for the analysis of disease occurrence. The NDVI maps are easy to produce using dedicated, remote sensing software. When testing the utility of NDVI measurements for the estimation of the likelihood of kala-azar presence (here considering new cases only) vis-à-vis distribution of the vector, the NDVI values varied not only with the seasons, but were also higher in the tree plantations than in the agricultural areas. The values were $\geq 0.5$ from July to February and dropped to their lowest level in the March-May period, probably due to seasonal lack of rainfall resulting in comparatively scanty crops.

Low NDVI values are generally positively correlated

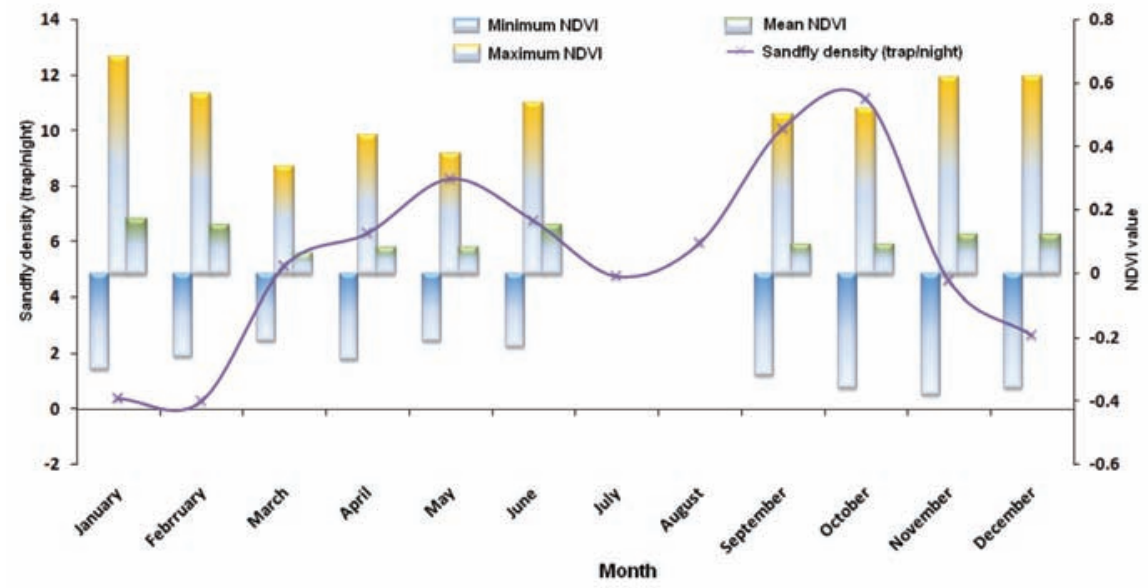

Fig. 7. Relation between the monthly vector density (number of $P$. argentipes per trap/per night) and the corresponding NDVI values* showing the relation between minimum NDVI and P. argentipes density, the maximum NDVI and P. argentipes density; and the mean NDVI and P. argentipes density.

* Missing NDVI measurements for July-August. 


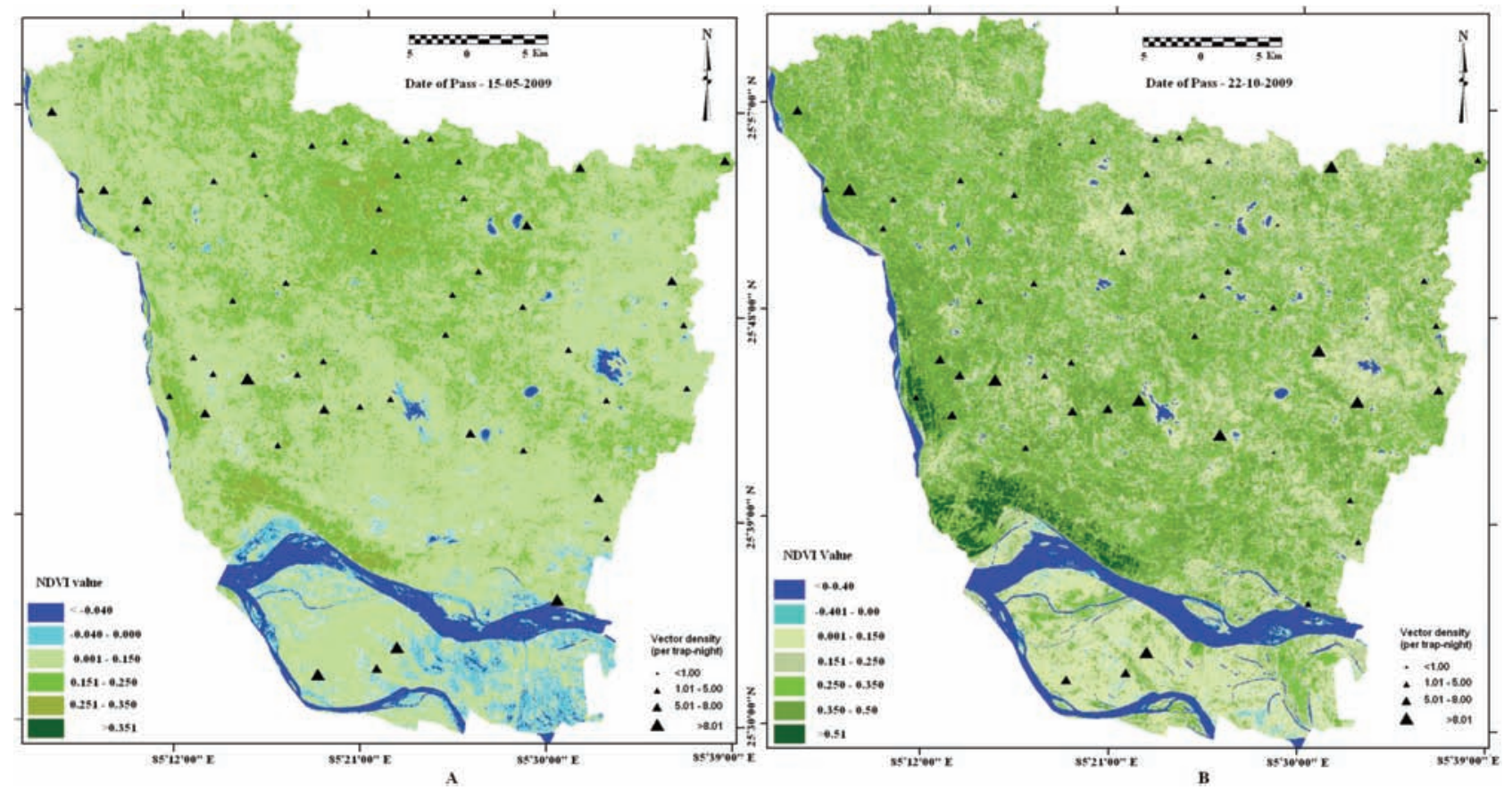

Fig. 8. Distribution of the pre-monsoon NDVI and vector density in 50 villages during summer (A); and that of post-monsoon NDVI and vector density in the same villages during the rainy season (B).

to the distribution of kala-azar (Gebre-Michael et al., 2004; Bhunia et al., 2010a). Based on the findings reported here, we feel that monthly counts of six or more minimum NDVI values above -0.2 , in particular moderate NDVI values (around 0.3) strongly indicate kala-azar endemicity. Although the NDVI decrease during the drier months (March-May) signifies less vegetation, and also indirectly points at lower levels of moisture during this part of the year, remaining pockets of vegetation may explain the observed high prevalence of localised kala-azar. The preservation of moisture due to remaining water-bodies within the study area is an alternative explanation. Also socio-economic variables, such as the degree of access to medical treatment and other factors that strongly influence the disease prevalence has been reported to influenced the outcome (Ahluwalia et al., 2003; Sharma et al., 2004; Kesari et al., 2010).

Combining the NDVI map with that of the spatial distribution of kala-azar in the pre-monsoon and the post-monsoon seasons demonstrates that areas with NDVI values $\geq 0.20$ generally coincide with areas with many reported kala-azar cases, which corroborates previous results (Elnaiem et al., 2003). The location of the $P$. argentipes habitats differs according to vegetation and the local environment (WHO, 1989). Environmental variables (i.e. soil moisture, temperature, humidity, land use/land cover and topography, etc.) contribute to $P$. argentipes abundance (Ghosh et al., 1999; Kishore et al., 2006; Guernaoui and Boumezzough, 2009; Bhunia et al., 2010b) and may also influence vector seasonality (Dinesh et al., 2001; Picado et al., 2010). However, if the minimum NDVI values are produced by water-bodies instead of empty land, these readings could be an indication of the relative humidity and damp surfaces favoured by $P$. argentipes for its egg and larvae, rather than signifying barren land (Bern et al., 2000; Sharma and Singh, 2008; Bhunia et al., 2011). Despite the low numbers of vector density often found together with high NDVI values $(>0.5)$, the cross-tabulation shows that the months with low counts of kala-azar and low mean NDVI values $(<-0.03)$ were also correlated with low $P$. argentipes densities. Although the interpretation is not straightforward, the analysis aids to infer a relationship between $P$. argentipes habitats and low NDVI values. Corroborating observations have been reported in previous studies (Bavia et al., 2005; Sudhakar et al., 2006). Presence of crop land within an area influences the disease indirectly by providing the necessary moisture for the breeding habitats, i.e. inside human dwellings and cattle sheds (Sudhakar et al., 2006). However, seasonal loss of leaves and the crop patterns are factors consistently affecting the NDVI readings.

The comparative study of the monthly distribution of new cases of kala-azar and the NDVI suggests that 
the incidence of kala-azar is concentrated in areas characterised by relatively low NDVI values, predominantly areas with peridomestic vegetation, which has also been reported by others (Thomson et al., 1999; Bavia et al., 2005; Bhunia et al., 2010a). Although it is not possible to discern the peridomestic vegetation at the imagery resolution used here $(30 \mathrm{~m})$, it is ideal for studying surface climatic condition and modelling vector populations within a biologically meaningful timeframe as the disease is direct dependent on the sand fly abundance. The study implies that both the monthly variation of NDVI and sand fly density must be considered risk factors. In the study, "false positive" results were found in areas with low NDVI values, while "false negative" results were observed in areas with high NDVI values. It would be possible to enhance the precision of the analysis by more clearly elucidating the relationship between the vector habitats and the NDVI values. The results can perhaps be attributed to the inclusion of areas with complex topographical and climatic conditions, diverse vegetation and differing NDVI values in regional units providing kala-azar index data.

Paradoxically, judging from reports on indoor residual spraying (IRS) campaigns in the endemic villages of Bihar, IRS seems to have resulted in an increase rather than a suppression of $P$. argentipes density (NICD, 1993; Dinesh et al., 2008). The reason for this is uncertain but serves to emphasise the need for further research on the many factors involved in kalaazar epidemiology. It is clear though, that the high seasonal fluctuation of the $P$. argentipes numbers during the year, which dominates the Vaishali district in the post-monsoon season, demonstrates the need for permanent awareness (through health education) together with rigorous epidemiological surveillance.

\section{Conclusion}

Our analyses, based on NDVI values, make it possible to better predict kala-azar endemicity, improving the potential for policy administrators to deploy control and prevention interventions in those areas experiencing problems. However, to produce detailed forecasts for kala-azar endemicity by means of NDVI qualification, it will be necessary to develop the model further considering the relationship between NDVI values and vector density vis-à-vis distribution of cases more precisely. Mapping of vegetation characteristics at the micro-level would be required to identify peridomestic vegetation associated with vector density.

\section{Acknowledgements}

We are thankful to Earth Explorer community, U.S. Department of the Interior, U.S. Geological Survey for freely supplying satellite data. We are grateful to Mr. Alok Ranjan, AIIMS, Patna for his kind assistance regarding the statistical analysis of the data. We further thank the District Malaria Office, Hajipur, Vaishali district (Bihar) for freely providing the VL data. Finally, we wish to thank NK Sinha, SA Khan, AK Mondal and Mukesh Kumar of Department of Vector Biology and Control, RMRIMS for their kind co-operation during the field visit. The funds to conduct this research work have been provided by the Indian Council of Medical Research (ICMR) through a SRF fellowship grant.

\section{References}

Ahluwalia IB, Bern C, Costa C, Akter T, Chowdhury R, Ali M, Alam D, Kenah E, Amann J, Islam M, Wagatsuma Y, Haque R, Breiman RF, Maguire JH, 2003. Visceral leishmaniasis. Consequences of a neglected disease in a Bangladeshi community. Am J Trop Med Hyg 69, 624-628.

Ashford RW, 2000. The leishmaniases as emerging and reemerging zoonoses. Int J Parasitol 30, 1269-1281.

Bavia ME, Madureira Trabuco Carneiro DD, da Costa Gurgel H, Madureira Filho C, Rodrigues Baarbosa MG, 2005. Remote sensing and geographic information systems and of risk of American visceral leishmaniasis in Bahia, Brazil. Parassitologia 47, 165-167.

Bern C, Joshi AB, Jha SN, Das ML, Hightower A, Thakur GD, Bista MB, 2000. Factors associated with visceral leishmaniasis in Nepal, bed-net use is strongly protective. Am J Trop Med Hyg 63, 184-188.

Bhunia GS, Kesari S, Chatterjee N, Pal DK, Kumar V, Ranjan A, Das P, 2011. Incidence of visceral leishmaniasis in the Vaishali district of Bihar, India: spatial patterns and role of inland surface water bodies. Geospat Health 5, 205-215.

Bhunia GS, Kesari S, Jeyaram A, Kumar V, Das P, 2010a. Influence of topography on the endemicity of Kala-azar: a study based on remote sensing and geographical information system. Geospat Health 4, 155-165.

Bhunia GS, Kumar V, Kumar AJ, Das P, Kesari S, 2010b. The use of remote sensing in the identification of the eco-environmental factors associated with the risk of human visceral leishmaniasis (kala-azar) on the Gangetic plain, in north-eastern India. Ann Trop Med Parasitol 104, 35-53.

Colacicco-Mayhugh MG, Masuoka PM, Grieco JP, 2010. Ecological niche model of Phlebotomus alexandri and P. papatasi (Diptera: Psychodidae) in the Middle East. Int J Health Geogr 9, 1-9.

Dhima RC, Dinesh D, 1992. An experimental study to find out the source of fructose to sandflies. Indian J Parasitol 16, 159 . 
160.

Dinesh DS, Dhima RC, 1991. Plant source of fructose to sandflies, particularly Phlebotomous argentipes in nature. J Comm Dis 23, 160-161.

Dinesh DS, Das P, Picado A, Davies C, Speybroeck N, Ostyn B, Boelaert M, Coosemans M, 2008. Long-lasting insecticidal nets fail at household level to reduce abundanc of sandfly vector Phlebotomous argentipes in treated houses in Bihar (India). Trop Med Int Health 13, 953-958.

Dinesh DS, Ranjan A, Palit A, Kishore K, Kar SK 2001. Seasonal and nocturnal landing/biting behaviour of Phlebotomus argentipes (Diptera: Psychodidae). Ann Trop Med Parasitol 95, 197-202.

Elnaiem DA, Schorscher J, Bendall A, Obsomer V, Osman ME, Mekkawi AM, Connor S, Ashford RW, Thomson MC, 2003. Risk mapping of visceral leishmaniasis, the role of local variation in rainfall and altitude on the presence and incidence of kala-azar in eastern Sudan. Am J Trop Med Hyg 68, 10-17.

Gebre-Michael T, Malone JB, Balkew M, Ali A, Berhe N, Hailu A, Herzi AA, 2004. Mapping the potential distribution of Phlebotomus martini and P. orientalis (Diptera: Psychodidae), vectors of kala-azar in East Africa by use of geographic information systems. Acta Trop 90, 73-86.

Ghosh KJ, Mukhopadhyay MM, Desai S, Sen Roy S, Bhattachariya A, 1999. Population ecology of Phlebotomous argentipes (Diptera: Psychodidae) in West Bengal, India. J Med Entomol 36, 588-594.

Guernaoui S, Boumezzough A, 2009. Habitat preferences of Phlebotomine sand flies (Diptera: Psychodidae) in Southwestern Morocco. J Med Entomol 46, 1187-1194.

Hamilton LC, 2009. Statistics with STATA, updated for version 10. 10 Davis Drive, Belmont, CA, USA.

Hilbe JM, 2011. Negative binomial regression - understanding and modeling overdispersed count data. $2^{\text {nd }}$ edition. Cambridge University Press.

Jopling WH, 1955. Long incubation period in Kala-azar. Brit Med J 2, 1013.

Kesari S, Bhunia GS, Kumar V, Jeyaram A, Ranjan A, Das P, 2010. Study of house-level risk factors associated in the transmission of Indian Kala-azar. Parasit Vectors 3, 94.

Kishore K, Kumar V, Kesari K, Dinesh DS, Kumar AJ, Das P, Bhattacharya SK, 2006. Vector control in leishmaniasis. Indian J Med Res 123, 467-472.

Krishnaswamy J, Bawa KS, Ganeshaiah KN, Kiran MC, 2009. Quantifying and mapping biodiversity and ecosystem services: utility of a multi-season NDVI based mahalanobis distance surrogate. 113, 857-867.

Leica Geosystems, 2008. Leica geosystems geospatial imaging ERDAS IMAGINE 9.2. Norcross, USA. Leica Geosystems Geospatial Imaging.

Lunetta RS, Elvidge CD, 1998. Remote sensing change detection. Epidemiology of the leishmaniases. Dermatol Clin 13,
505-523.

Magill AJ, 1995. Epidemiology of the leishmaniases. Dermatol Clin 13, 505-523.

Markham BL, Storey JC, Williams DL, Irons JR, 2004. Landsat sensor performance, history and current status. IEEE T Geosci Remote 42, 2691-2694.

Myneni RB, Hall FB, Sellers PJ, Marshak AL, 1995. The interpretation of spectral vegetation indices. IEEE T Geosci Remote 33, 481-486.

NICD, Directrate of General of Health Services, 1993. Proceedings of workshop on entomological and vector control aspects of kala-azar. Sham Nath Marg, Delhi, 54 pp.

Nieto P, Malone JB, Bavia ME, 2006. Ecological niche modeling for visceral leishmaniasis in the state of Bahia, Brazil, using genetic algorithm for rule-set prediction and growing degree day-water budget analysis. Geospat Health 1, 115-126.

Pavlovsky EN, 1996. Natural nidality of transmissable diseases, with special reference to the landscape epidemiology of zooanthroponse. Urbana, IL, University of Illinois Press, USA.

Pearson RD, Jeronimo SMB, de Queiroz Sousa A, 1999. Leishmaniasis. In: Tropical Infectious Diseases. Principles, pathogens, and Practice (Guerrant RL, Walker DH, Weller PF, eds). Philadelphia, Churchill Livingstone, pp. 797-813.

Picado A, Das ML, Kumar V, Dinesh DS, Rijal S, Singh SP, Das P, Coosemans M, Boelaert M, Davies C, 2010. Phlebotomous argentipes seasonal patterns in India and Nepal. J Med Entomol, 47, 283-286.

Ramaswamy V, Anderson EW, DeSarbo WS, 1994. A disaggregate negative binomial regression procedure for count data analysis. Manag Science 40, 405-417.

Ranjan A, Sur D, Singh VP, Siddique NA, Manna B, Lal CS, Sinha PK, Kishore K, Bhattacharya SK, 2005. Risk factors for Indian kala-azar. Am J Trop Med Hyg 73, 74-78.

Redhu NS, Dey A, Balooni V, Singh S, 2006. Leishmania-HIV coinfection, an emerging problem in India. AIDS 20, 1213-1215.

Rees PH, Kager PA 1987. Visceral leishmaniasis and postkalaazar dermal leishmaniasis. In: The Leishmaniases in Biology and Medicine (Peters W, Killick-Kendrick R, eds). London Academic Press, pp. 584-615.

Ridout M, Demétrio CGB, Hinde J, 1998. Models for count data with many zeros. International Biometric Conference, Cape Town. Available at https://www.kent.ac.uk/smsas/personal/msr/webfiles/zip/ibc_fin.pdf (accessed on December 1998).

Rouse JW, Haas RH, Schell JA, Deering DW, Harlan JC, 1974. Monitoring the vernal advancements and retrogradation (greenwave effect) of nature vegetation. NASA/GSFC Final Report. Greenbelt, MD, NASA.

Sanayal RK Banerje DP, Ghosh TK, Ghose JN, Misra BS, Roy YP, Rao CK, 1979. A longitudinal review of Kala-azar in Bihar. J Comm Dis 11, 149-169.

Sharma BP, Maskay NM, Adhikari SR, Andrews JR, Joshi AB, 
Wijeyaratne P, Joshi SD, 2004. Socio-economic determinants of Kala-azar in Nepal. J Nepal Health Res Counc 2, 35-42.

Sharma U, Singh S, 2008. Insect vectors of Leishmania, distribution, physiology and their control. J Vector Borne Dis 45, 255-272.

Short HE, Barraud PJ, Crighead AC, 1927. Transmission experiments in Indian kala-azar with Phlebotomus argentipes. Indian J Med Res 14, 589-600.

Srivastava P, Dayama A, Mehrotra S, Sundar S, 2011. Diagnosis of visceral leishmaniasis. Trans R Soc Trop Med Hyg 105, 1-6.

State Health Society of Bihar, 2007. Available at: http://statehealthsocietybihar.org/ (accessed on October 2009).

Sudhakar S, Srinivas T, Palit A, Kar SK, Battacharya SK, 2006. Mapping of risk prone areas of kala-azar (visceral leishmaniasis) in parts of Bihar state, India: an RS and GIS approach. J Vector Borne Dis 43, 115-122.

Swaminath, CS et al., 1942. Transmission of Indian kala-azar to man by the bite of P. argentipes Annadale and Brunetti. Indian J Med Res 30, 473-477.

Thomson MC, Elnaiem DA, Ashford RW, Connor SJ, 1999. Towards a Kala-azar risk map for Sudan: mapping the potential distribution of $\mathrm{Ph}$. orientalis using digital data of environmental variables. Trop Med Int Health 4, 105-113.

Tucker CJ, 1979. Red and photographic infrared linear combinations for monitoring vegetation. Remote Sens Environ 8, $127-150$.

Wall L, Larocque D, Léger PM, 2008. The early explanatory power of NDVI in crop yield modelling. Int J Remote Sens 29, 2211-2225.

WHO, 1989. Geographical distribution of arthropod-borne diseases and their principal vectors. VBC 967, 6-17.

WHO, 2008. Responding to emerging and re-emerging vector borne disease. Regional Office of Southeast Asia. Provisional agenda item 13. Sixty-first sessions, SEARO, New Delhi, India, 8-11 September. 